\title{
Uptake of Family Planning Services Among Refugees in South-South Nigeria: The Impact of Medical Outreaches
}

\author{
Abayomi Joseph Afe*, Idowu Araoyinbo, Yakubu Aliyu, Olanrewaju \\ Alabi, Jacque Karungi, Polycap Takou and Theresa Adah \\ UNFPA, Cross River State Sub-office, Calabar, Nigeria \\ *Corresponding Author: Abayomi Joseph Afe, UNFPA, Cross River State Sub-office, \\ Calabar, Nigeria.
}

Received: December 24, 2020

Published: January 22, 2021

(C) All rights are reserved by Abayomi Joseph

Afe., et al.

\begin{abstract}
Refugees especially the female adolescents and youths have highly vulnerable due to high risk of sexual violence, exploitation and abuse, and early or forced marriage. Adolescent pregnancies are reported to be higher among refugees or displaced persons than the non-displaced persons at 30 and 19\% respectively. They also have low contraceptive prevalence rate and have accessibility and availability challenges in procuring family planning services. To mitigate these challenges, routine family planning outreaches were conducted to two refugee camps in south-south region of Nigeria over a period of 12 months.

A total of 308 men and women received modern contraceptives during the outreaches. This is about $4 \%$ of the total population of men and women within the reproductive age group. Also, only 179 women and girls within the reproductive age group received modern contraceptives during the outreaches, which also account for $4 \%$ of all women within reproductive age group residing in the camps. About $46 \%$ received condoms only, $54 \%$ received implants and condoms, $2 \%$ received both injectables and condoms and another $2 \%$ received oral pills and condoms.

The low uptake of contraceptives in this study is similar to the results in other studies in similar settings. Factors responsible could include inadequate knowledge on contraceptives, fear of side effects, partner prohibitions, poor access to modern contraceptives.
\end{abstract}

The pattern of contraceptive types distributed could reflect availability of contraceptives and fulfilling the eligibility criteria by the clients.

Keywords: Contraceptive; Family Planning

\section{Introduction}

Refugees are people fleeing conflict or persecution. They are defined and protected in international law, and must not be expelled or returned to situations where their life and freedom are at risk. Their population is rapidly increasing worldwide with the number reaching 25.9 million [1].

Refugees are vulnerable persons because of the conflicts, insecurity, the violence and poverty they often face [2]. Refugees es- pecially the youths have a large unmet need for contraception, yet face challenges that limit its use. Female refugee adolescents are highly vulnerable due to high risk of sexual violence, exploitation and abuse, and early or forced marriage [3,4]. Adolescent pregnancies are reported to be higher among refugees or displaced persons than the non-displaced persons at 30 and 19\% respectively [5].

Study [6] on perceptions, knowledge, access and attitudes toward contraceptive among refugee youths living in a refugee camp 
in Nigeria revealed that most experienced difficulty gaining access to family planning services, which are not available in the camp. Most also had little correct information about contraceptives; many had misperceptions about its safety, believing that contraceptives are dangerous and that chemicals in contraceptives can damage their reproductive system. These challenges have resulted in the low use of contraceptives (31.6\% use last sex) and many unintended pregnancies, which have caused some refugee girls to drop out of school.

Nigerian has very poor Family Planning indices with Total Fertility Rate at 5.5, any method of Contraceptive Prevalence Rate (CPR) at 15\% (10\% modern methods and 5\% traditional methods), high family planning knowledge (any method 85\% female and 95\% male, modern method $84 \%$ female and $94 \%$ male) and high unmet need for Family Planning at $16 \%$. The country initially set a target of achieving CPR of $36 \%$ by December 2018 which was reviewed down to $27 \%$ by 2020 [7].

There are over 7.3 million Women of Reproductive Age (WRA) who are currently non-users but have unmet need to start using Modern Family Planning methods.

According to the NDHS 2018, Cross River had a CPR of 18.9\%, Total Fertility Rate of 3.7 and teenage pregnancy rates of $14 \%$.

The asylum seekers are mainly coming from Akwaya, Otu, Eyumojock, Nsan, Dadi and Bodam in Cameroon's South-West Anglophone region. They are being hosted across some 87 local communities in the states of Akwa-Ibom, Benue, Cross River and Taraba. According to the UNHCR Nigeria-Cameroon Refugees Registration Dashboard September 2020, the total registered refugees from Cameroon are 60,494. Out of this total, 36,866 are living in Cross River State [8]. The receiving communities largely are Amana, Akamkpa, Agbokim, Ikom/Ajasso and Boki in Cross River State.

Women and children represent about 80 percent of the approximately 10,000 refugees registered so far in eastern Nigeria's Cross River state. Some of these children who are unaccompanied and separated from parents are particularly affected by difficult access to food and the lack of subsistence opportunities. For women, the lack of work combined with the over-stretched reception facilities, creates a higher risk of sexual and gender-based violence, particularly from survival sex. Incidents of domestic violence, as well as cases of teenage pregnancies involving girls as young as 14 , have also been reported.

Many of the health interventions to refugee communities have focused on provision of care for non-reproductive or non-sexual health services such as the management of communicable and non-communicable diseases like water-borne and food-borne infections, malaria and nutritional disorders.

Many studies [9] have reported accessibility-related barriers to family planning services in refugees camp setting such barriers include limited availability of certain methods, especially longacting and permanent method, distant service delivery points, cost of transport, lack of knowledge about different types of methods, misinformation and misconceptions, religious opposition, cultural factors, language barriers with providers, and provider biases.

To mitigate the accessibility barrier to contraceptives, cyclical free medical outreaches targeted at providing family planning services were conducted to provide contraceptives to the refugees in the two refugee camps at Ogoja Local Government Area in Cross River state in south-south region of Nigeria.

\section{Materials and Methods}

- Study Design: Retrospective analysis of the reports generated during the conduct of two outreaches to the two refugee camps in Ogoja LGA, Cross River state between 2019 and 2020.

- Location: The two refugee camps known as Adagom and Okende Refugee camps were established in 2018 by the Cross-River state government to cater for the influx of Cameroonians refugees from southern Cameroun. There are two primary healthcare centers in the two camps to provide for the healthcare needs of the residents. The population of the registered residents in the two camps is shown in the table below.

- Intervention: A mobile medical team comprising of nurses and health educators was constituted to execute the medical outreach. A planning committee made up of important stakeholders from the state ministry of health, local government health team, funders and implementing partners was also constituted to plan for the outreaches in terms of the funding and logistic support and technical assistance. A pre- 
implantation advocacy was carried out to the sites and the hosting communities to prepare them for visit by the mobile team on agreed dates.

The medical outreach was carried out on over 5 days at the two refugee settlements by two different mobile teams concurrently. The health centers in the camps served as locations of the outreaches where family planning counselling and contraceptives were provided in confidential setting.

Family planning counselling: This was provided as part of group health talk to the refugees who came out for the outreaches. Information provided included definition of family planning, benefits of family planning, types of contraceptives and eligibility criteria for the different types of contraceptives.

Double Protection: A combination of a barrier method using male or female condom and any of hormonal method (oral pill, injectable, implant) was provided for refugees who consented and qualified based on established criteria.

\section{Results and Discussion}

\begin{tabular}{|l|c|c|c|c|}
\hline S/N & Age Group & Female & Male & Percentage \\
\hline 1 & 0 -4yrs & 1,649 & 1,719 & $14.6 \%$ \\
\hline 2 & 5-11yrs & 2,225 & 2,177 & $24.5 \%$ \\
\hline 3 & $12-17 y r s$ & 1,270 & 1,262 & $14.7 \%$ \\
\hline 4 & $18-59 y r s$ & 4,261 & 3,108 & $42.8 \%$ \\
\hline 5 & $60+y r s$ & 297 & 181 & $3.4 \%$ \\
\hline 6 & Total & 8,451 & 9,732 & $100 \%$ \\
\hline
\end{tabular}

Table 1: Population of Refugees in Refugee Camps in Ogoja LGA, Cross River state as at 2019 [10].

\begin{tabular}{|l|c|c|c|}
\hline S/N & Gender/Age groups & Number & Frequency \\
\hline 1 & Male Population & 9,732 & $54 \%$ \\
\hline 2 & Female Population & 8,451 & $46 \%$ \\
\hline 3 & Total & 18,183 & \\
\hline & $\begin{array}{c}\text { Women in } \\
\text { Reproductive Age }\end{array}$ & 4,261 & $\begin{array}{c}44 \% \text { of female } \\
\text { population, } \\
23 \% \text { of total } \\
\text { population }\end{array}$ \\
\hline
\end{tabular}

Table 2: Population distribution of Refugees in Ogoja camps, Cross River.

\begin{tabular}{|l|c|c|c|}
\hline S/N & Gender & Number & Percentage \\
\hline 1 & Female & 179 & $58 \%$ \\
\hline 2 & Male & 129 & $42 \%$ \\
\hline & Total & 308 & $100 \%$ \\
\hline
\end{tabular}

Table 3: Distribution of Clients that received FP services during outreach.

\begin{tabular}{|l|c|c|}
\hline & Number & Frequency \\
\hline New Acceptor & 339 & $76 \%$ \\
\hline Revisit & 106 & $24 \%$ \\
\hline Total & 445 & $100 \%$ \\
\hline
\end{tabular}

Table 4: Distribution into new acceptor and revisit.

\begin{tabular}{|l|c|c|c|}
\hline S/N & $\begin{array}{c}\text { Contraceptive } \\
\text { Types }\end{array}$ & New Acceptor & Revisit \\
\hline 1 & Condoms & $68 \%$ & $32 \%$ \\
\hline 2 & OCPs & $38 \%$ & $62 \%$ \\
\hline 3 & Implanon & $100 \%$ & $0 \%$ \\
\hline 4 & Jadelle & $100 \%$ & $0 \%$ \\
\hline 5 & Levoplant & $100 \%$ & $0 \%$ \\
\hline 6 & Depoprovera & $33 \%$ & $67 \%$ \\
\hline 7 & Noristerat & $33 \%$ & $67 \%$ \\
\hline
\end{tabular}

Table 5: Contraceptive Types and Categories of clients.

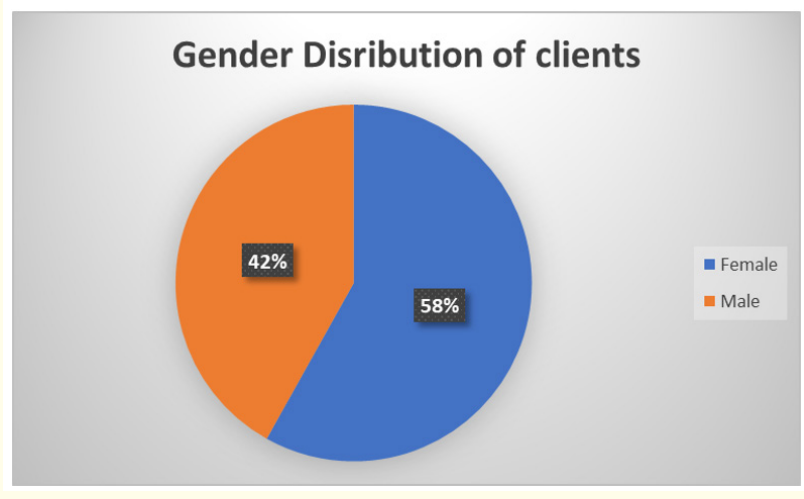

Figure 1: Gender distribution of clients. 


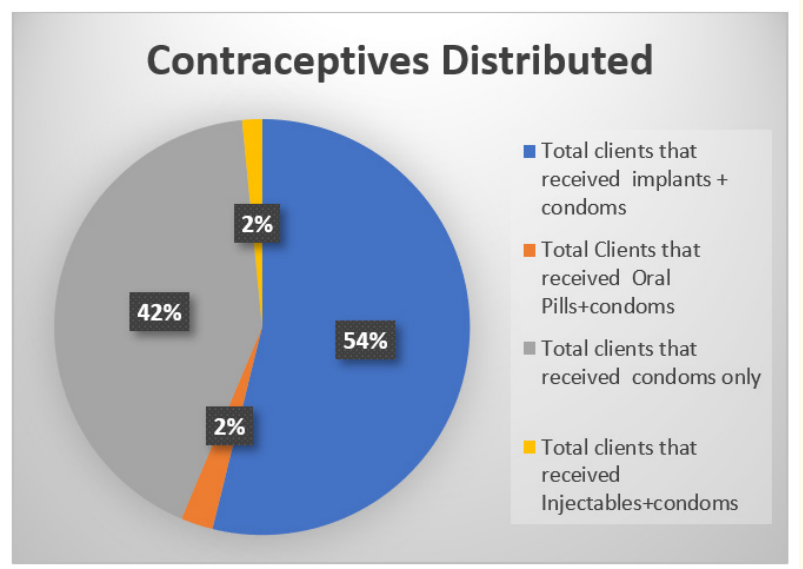

Figure 2: Types of Contraceptives distributed.

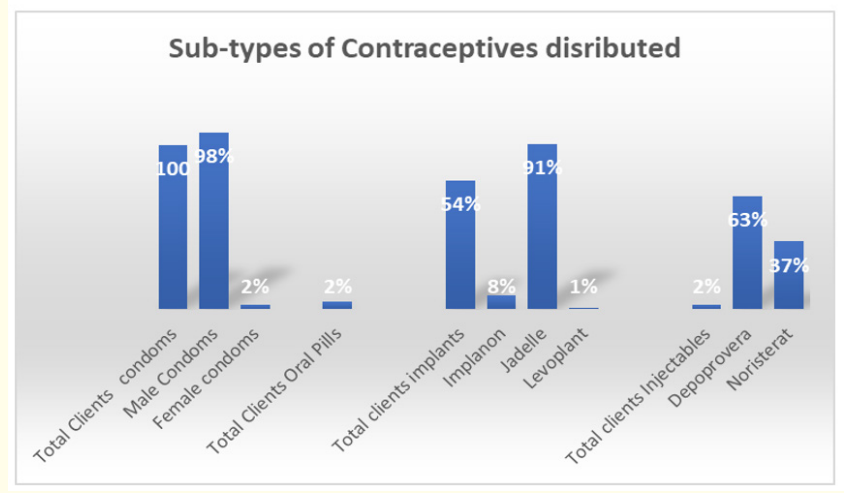

Figure 3: Subtypes of contraceptives distributed.

The two camps accommodated 18,183 refugees comprising of $54 \%$ males and $46 \%$ female. There were about 4,261 women in reproductive age group, accounting for $44 \%$ of the female population and $23 \%$ of the entire camps population respectively. There were about 7,369 men and women in the reproductive age category accounting for the largest proportion (42.8\%) of the camps residents followed by children in the 5-11yrs age category. Elderly people from $60 y$ rs and above are the least populated members of the camps $(3.4 \%)$.

Of all the camp residents, only 308 men and women consented and received modern contraceptives during the outreaches. This is about $4 \%$ of the total population of men and women within the reproductive age group. Further analysis showed that only 179 women and girls within the reproductive age group received modern contraceptives during the outreaches. This figure also represents $4 \%$ of all women within reproductive age group residing in the camps.

The family planning services rendered include counselling and contraceptives distribution. More female (58\%) than males (42\%) received these services during the outreaches. All the clients received condoms (100\%), but 54\% received both condoms and implants, while $2 \%$ received both condoms and oral pills, and another $2 \%$ received both condoms and injectables.

About $42 \%$ of the clients received condoms only; majority of these clients are male. Of the number that received condoms, $98 \%$ received male condoms and $2 \%$ received female condoms. Among the implant's users, 91\% received Jadelle,8\% received implanon and $1 \%$ received Levoplant. But for those that received injectables contraceptives, 63\% received Depo-Provera and 37\% received Noristerat. This distribution pattern of contraceptive reflects the choice of the clients and the availability of the commodities. The skill set needed by the provider was enough and therefore may not have been a factor in the pattern of the contraceptive types. The fact that a meagre $4 \%$ (179) of women within the reproductive age group were reached during the outreach is abysmally poor. This might be due to limited resources and the short time frame allotted for the outreach. But several studies from other refugee settings have reported similar findings of low modern contraceptive use among refugees $[9,11,12]$. For example, in a multi country study of refugee settings, current use of contraceptives was reported to be only $4 \%$. In addition, a study among refugees in Ghana reported current contraceptive use of 7.3\% [12]. In previous studies, low prevalence of modern contraceptive use in refugee settings was attributed to inadequate knowledge on contraceptives, fear of side effects and partner prohibitions [9,13]. The low prevalence has also been attributed to poor access to modern contraceptives as demonstrated by a study in Uganda which showed that $70.2 \%$ of the refugee population studied could not access a contraceptive source within 10 min' walk from their homes.

\section{Conclusion}

With just $4 \%$ of the WRA reached during the outreach, there is still a huge gap in the provision of contraceptive among refugees in 
Cross river state. This directly increase the unmet need for family planning services in the state and the country as a whole. There is need to support regular outreaches program that focus on providing contraceptives to the residents of the refugee camps. The pattern of distribution of the different types of contraceptives should also inform the logistic of the commodities supply in the future outreach.

\section{Acknowledgement}

- United Population Fund Agency (UNFPA)

- United Nations High Commission for Refugees (UNHCR)

- Cross River State Ministry of Health.

\section{Conflict of Interest}

The authors have no conflict of interest to declare.

\section{Bibliography}

1. UNHCR. Figures at a glance (2019).

2. Bakesiima R., et al. "Modern contraceptive use among female refugee adolescents in northern Uganda: prevalence and associated factors". Reproductive Health 17 (2020): 67.

3. UNHCR. Comprehensive refugee response framework Uganda, the way forward (2017).

4. WRC. Facts and figures (2020).

5. Profamilia. Encuestas: Fecundidad y Salud general (2000): 48.

6. Okanlawon K., et al. "Contraceptive Use: Knowledge, Perceptions and Attitudes of Refugee Youths in Oru Refugee Camp, Nigeria". African Journal of Reproductive Health / La Revue Africaine De La Santé Reproductive 14.4 (2010): 16-25.

7. National Family Planning Communication Plan (2017-2020). Strategy for Increasing the use of Modern Contraceptives in Nigeria. Federal Ministry of Health, Abuja, Nigeria.

8. https://reliefweb.int/sites/reliefweb.int/files/resources/ UNHCR\%20Nigeria\%20-\%20Cameroon\%20Refugees\%20 Registration\%20Dashboard_September\%202020.pdf

9. Mihoko Tanabe., et al. "Family planning in refugee settings: findings and actions from a multi-country study". Conflict and Health 11 (2017): 9.

10. UNHCR Nigeria - Cameroon Refugees Registration Dashboard. UNHCR Nigeria, HDX | nigabim@unhcr.org | UPDATED (2020).
11. UNHCR. Baseline study: documenting knowledge, attitudes and practices of refugees and the status of family planning services in UNHCR's operations in Nakivale refugee settlement, Uganda (2011).

12. Ganle JK., et al. "Risky sexual behaviour and contraceptive use in contexts of displacement: insights from a cross-sectional survey of female adolescent refugees in Ghana". International Journal for Equity in Health 18.1 (2019): 127.

13. Ochako R., et al. "Barriers to modern contraceptive methods uptake among young women in Kenya: a qualitative study". BMC Public Health 15.1 (2015): 118.

\section{Assets from publication with us}

- Prompt Acknowledgement after receiving the article

- Thorough Double blinded peer review

- Rapid Publication

- Issue of Publication Certificate

- High visibility of your Published work

Website: www.actascientific.com/

Submit Article: www.actascientific.com/submission.php Email us: editor@actascientific.com

Contact us: +919182824667 